\title{
Prevalence of Helicobacter pylori infection among children with primary nephrotic syndrome: a cross-sectional study
}

\author{
Ahmed Mahmoud ${ }^{1}$, Ashraf Bakr ${ }^{1}$, Afaf Elsaid ${ }^{2}$, Yahya Wahba ${ }^{1}$
}

1. Mansoura University, Faculty of Medicine, Department of Pediatrics.

2. Mansoura University Children's Hospital, Biochemistry Section.

\begin{abstract}
Background: Limited data are available about the prevalence of helicobacter pylori (H.pylor $)$ infection among primary NS children.

Objectives: To assess the frequency and risk factors of H.pylori infection among children with primary NS.

Methods: A cross-sectional study was carried out in Mansoura University Children's Hospital, Egypt during the period from 2017 to 2019 including 100 NS children (NS group) and 100 healthy controls. NS group included 88 steroid sensitive (SSNS) and 12 steroid resistant (SRNS) cases. All patients were assessed for H.pylori infection using H.pylori stool antigen (HpSA) test. Statistical analysis was done using chi-square, fisher exact and Mann-Whitney tests.

Results: With regard to HpSA test results, no significant differences were detected between control and NS groups $(\mathrm{p}=$ $0.193)$ and between SSNS and SRNS groups $(\mathrm{p}=0.286)$. Concerning total biopsied cases and MCD (proven plus presumed) cases, no significant differences were found between those with positive and negative HpSA test $(\mathrm{p}=0.648$ and 0.126 , respectively). The high dose of steroid therapy was associated with a higher risk of H.pylori infection among NS group (Odds ratio $=3.8 ; 95 \%$ confidence interval $=1.3-11.3)$.

Conclusion: The current study negates the increased risk of H.pylori infection in children with primary NS.

Keywords: Children; H.pylori; primary nephrotic syndrome.

DOI: https://dx.doi.org/10.4314/ahs.v20i4.15.

Cite as: Mabmoud A, Bakr A, Elsaid A, Wabba Y. Prevalence of Helicobacter pylori infection among children with primary nephrotic syndrome: a cross-sectional study. Afri Health Sci. 2020;20(4):1624-31. https:/ / dx.doi.org/10.4314/abs.v20i4.15.
\end{abstract}

\section{Introduction}

Nephrotic syndrome (NS) is a relatively common pediatric disease ${ }^{1}$ with an immunological background proved by the successful therapeutic effects of steroids and immune-modulating drugs ${ }^{2,3}$.

Helicobacter pylori (H.pylori) are gram-negative bacteria that selectively colonize the gastric mucosa. The organism is spiral shaped with three to five polar flagella, and characterized by being urease, oxidase and catalase positive $^{4}$. A recent meta-analysis revealed that about four billion persons were colonized with H.pylori worldwide in $2015^{5}$. In developing countries, H.pylori infection is highly prevalent and represents a great challenge ${ }^{6,7}$. In Egypt, this infection is very common reaching up to $72 \%$ among school children ${ }^{8}$.

\section{Corresponding author: \\ Yahya Wahba, \\ Mansoura University, Faculty of Medicine, \\ Department of Pediatrics. \\ ORCID (https://orcid.org/0000-0001-7479-7866) \\ Emails: wahbayahya2007@mans.edu.eg; \\ yahyawahba@ymail.com}

Now, there is agreement that H.pylori is not only associated with gastric diseases but also with immune-mediated extra-gastrointestinal disorders ${ }^{9}$. It is associated with atopic dermatitis, Henoch-Schönlein purpura, idiopathic thrombocytopenic purpura, systemic sclerosis, recurrent aphthous stomatitis, alopecia areata and Sjogren's syndrome. In addition, H.pylori eradication could help in management of Behcet's disease. These effects could be attributed to the chronic systemic inflammatory state induced by the organism ${ }^{10,11}$.

Limited trials were conducted in the pediatric age group to detect the association between H.pylori infection and NS with contradictory results ${ }^{9,12,13}$. The current study assessed the frequency of H.pylori infection among children with primary NS and the related risk factors.

\section{Materials and methods}

\section{Study design and participants}

A cross-sectional comparative study was carried out from January 2017 to January 2019 including 100 primary NS children (NS group) and 100 healthy controls. NS patients were recruited from both inpatient wards and outpatient nephrology clinics of Mansoura Univer- 
sity Children's Hospital, Egypt. NS group included 88 steroid sensitive (SSNS) and 12 steroid resistant (SRNS) cases. Among SSNS cases, 43 patients were infrequent relapsers, 30 patients were steroid dependent, 12 patients were first attack and 3 patients were frequent relapsers. The controls were recruited from children attending the same hospital with minor complaints e.g. mild gastroenteritis and pharyngitis.

Our study was accepted by Institutional Research Board of Medical Faculty of Mansoura University, Egypt (Code No: MS/16.08.35) and followed the Helsinki Declaration of 1975 , as revised in 2000. Informed written consents were obtained from legal guardians of all study participants.

All primary NS children with persistent dyspeptic symptoms were included. NS was defined as the presence of edema, serum albumin $<2.5 \mathrm{gm} / \mathrm{dl}$, nephrotic range proteinuria ( $\geq 40 \mathrm{mg} / \mathrm{m}^{2} / \mathrm{h}$ or protein/creatinine ratio $>2 \mathrm{mg} / \mathrm{mg}$ ) and elevated serum cholesterol and triglycerides levels ${ }^{14}$. Patients were labeled as SSNS if in remission, infrequent relapse, frequent relapse or steroid dependent. Steroid resistance means no remission despite daily prednisolone therapy at a dose of $2 \mathrm{mg} /$ $\mathrm{kg} / \mathrm{d}$ for four weeks. Patients were in remission if urinary albumin was trace or nil for three consecutive early morning specimens. Frequent relapse was defined as two or more relapses in the initial six months or more than three relapses in any 12 months of treatment. Steroid dependence means occurrence of two consecutive relapses within two weeks of steroid discontinuation or when on alternate day steroids ${ }^{15}$.

Patients were excluded if secondary NS, received H.pylori treatment within the last three months before participation in the study, received proton pump inhibitors within two weeks prior to sampling, or on an antibiotic treatment at the time of the testing procedure.

\section{Sample size}

It was calculated using $G^{*}$ Power 3.0.10 program. Based on $65.6 \%$ prevalence among NS patients and $44.4 \%$ among controls (Moriyama et al., 2006) ${ }^{16}$, and assuming $\alpha$ (type I) error $=0.05$ and $\beta$ (type II) error $=0.2$ and power $=80 \%$; a sample size of 88 children was assumed for each group with an effect size $=0.425$. We added $15 \%$ to overcome drop out, and the presumed sample size was 100 children in each group.

\section{History and clinical examination}

Patients were subjected to detailed history taking with special emphasis on the response to steroids and the dose and duration of steroids therapy. Treatment of an initial episode of NS included oral prednisolone as a single daily dose starting at $2 \mathrm{mg} / \mathrm{kg} / \mathrm{d}$ to a maximum $60 \mathrm{mg} / \mathrm{d}$ for 4 weeks followed by alternate-day dosing as a single daily dose starting at $1.5 \mathrm{mg} / \mathrm{kg}$ (maximum $40 \mathrm{mg} / \mathrm{d}$ ) and continued for 2-5 months with gradual dose tapering. The steroid therapy should be given for at least 12 weeks $^{17}$. Low-dose steroid was initiated for relapse of SSNS using oral prednisolone $1 \mathrm{mg} / \mathrm{kg} / \mathrm{d}$ (maximum $40 \mathrm{mg} / \mathrm{d}$ ) for a minimum of 7 days. Once the patient was in remission and/or had completed 7 days of steroid therapy, gradual tapering of prednisolone was done over a month. If the patient developed progressive edema or failed to get remission within 7 days of therapy initiation, the prednisolone dose was increased to the standard high-dose regime $(2 \mathrm{mg} /$ $\mathrm{kg} / \mathrm{d})^{18}$. All patients were assessed for gastritis symptoms as dyspepsia, vomiting, recurrent abdominal pain and epigastric tenderness.

\section{Laboratory evaluation}

All participants were subjected to urine analysis, 24-h urine protein assessment/protein-creatinine ratio and serum levels of creatinine, albumin, cholesterol and triglycerides. Data about renal histopathology were retrieved from patients' files. Renal biopsy was done for only 38 cases (29 SSNS and 9 SRNS cases). Four SSNS cases (steroid dependent) and three SRNS cases were not biopsied due to patient guardians' refusal or current contraindications for renal biopsy (bleeding tendency).

H.pylori infection was assessed using H.pylori stool antigen test (HpSA test; ImmunoCard STAT! ${ }^{\circledR}$; Meridian Bioscience Europe, European Union; Catalog Number: 750220). HpSA test is simple, rapid, non-invasive, and can detect the active current infection. It is considered as a $2^{\text {nd }}$ generation rapid lateral flow immunoassay test using monoclonal anti-H.pylori antibodies. The specificity and sensitivity of the test are $99.2 \%$ and $94.3 \%$, respectively as reported in the manufacturer's product information. The test value for H.pylori diagnosis was well recognized in previous reports ${ }^{19}$.

Stool samples were collected from all study participants, transported in airtight containers and tested as soon as possible but might have been held at $2^{\circ}-8^{\circ} \mathrm{C}$ for 72 hours before testing. If testing could not be done with- 
in this time frame, specimens were frozen immediately upon receipt and stored at $-20^{\circ}$ to $-80^{\circ} \mathrm{C}$ until tested. Each stool sample (5-6 ml) was mixed thoroughly with $1 \mathrm{ml}$ diluent in a test tube. Then, we dipped the reaction strip in the test tube for 10 seconds, and read the results after 5 minutes. We considered the test negative if only a blue colored band (the control line) appeared across the white central area of the reaction strip, and positive if an additional pink red band (the test line) also appeared. Any pink red line, even very weak, was considered positive. The band intensity varied according to the concentration of the antigen in the specimen. Any color or line appearing after 10 minutes had no diagnostic value. The test was considered invalid if the control band was absent.

\section{Statistical analysis}

SPSS version 21 was used to analyze data. Kolmogorov-Smirnov test was used to assess the data for normality. Qualitative data were described using numbers and percent. Chi-square and Fisher exact tests were used to describe the associations between the categorical variables. Non-parametric continuous variables were expressed as median (min-max), and analyzed using Mann-Whitney test. Logistic regression analysis was done for the risk factors associated with positive HpSA test among NS group. $\mathrm{P} \leq 0.05$ was considered significant.

\section{Results}

Both NS and control groups were matched for the gender and age. The median age of NS group was 9 (1-17) years, while that of the control group was 8.5 (2-14) years $(p=0.083)$. Males constituted the majority of the study participants (67 children in NS group and 57 children in control group, $\mathrm{p}=0.145)$.

With regard to HpSA test results, no significant difference was found between control and NS groups (Table $1, \mathrm{p}=0.193)$. Also, table 2 shows no significant difference between SSNS and SRNS subgroups $(p=0.286)$.

Table 1 Distribution of results of helicobacter pylori stool antigen test among children with primary nephrotic syndrome (NS) and control groups

\begin{tabular}{|l|l|l|l|}
\hline HpSA test & NS group $(n=100)$ & Control group $(n=100)$ & p value \\
\hline Positive & $44(44 \%)$ & $35(35 \%)$ & \\
\cline { 1 - 2 } Negative & $56(56 \%)$ & $65(65 \%)$ & \multirow{2}{*}{0.193} \\
\hline
\end{tabular}

HpSA: Helicobacter pylori stool antigen, NS: Nephrotic syndrome. Data are shown as numbers and percent and analyzed by chi-square test.

No significant difference was detected between total biopsied NS cases $(\mathrm{n}=38$ ) with positive HpSA test $(20,52.63 \%)$ and negative HpSA test $(18,47.37 \%)$ (p $=0.648)$. Mesangioproliferative glomerulonephritis and minimal change disease (MCD) were more frequent among biopsied NS group \{16 patients (42.1\%) and 10 patients $(26.3 \%)$, respectively $\}$ followed by focal segmental glomerulosclerosis (5 patients, 13.2\%), membranoproliferative glomerulonephritis (4 patients, $10.5 \%)$ and three patients $(7.9 \%)$ had $\operatorname{IgA}$ nephropathy. MCD was the most frequent renal histopathology among biopsied NS patients with positive HpSA test (9 patients) with a significant difference when compared to those with negative HpSA test (1 patient) ( $p$ $=0.013)$. With regard to non-biopsied SSNS patients mostly presumed to be MCD ( $\mathrm{n}=59), 21$ cases had positive $\mathrm{HpSA}$ test and 38 cases had negative HpSA test. Concerning the total MCD cases (proven plus presumed cases, $n=69$ ), no significant difference was reported between those with positive HpSA test $(\mathrm{n}=30$; $43.48 \%)$ and negative HpSA test $(\mathrm{n}=39 ; 56.52 \%)(\mathrm{p}=$ 0.126) (Table 3). 
Table 2 Distribution of results of helicobacter pylori stool antigen test among children with steroid sensitive NS and steroid resistant NS

\begin{tabular}{|l|l|l|l|}
\hline HpSA test & Steroid sensitive NS (n=88) & Seroid resistant NS (n=12) & p value \\
\hline Positive & $37(42 \%)$ & $7(58.3 \%)$ & \\
\hline Negative & $51(58 \%)$ & $5(41.7 \%)$ & \multirow{2}{*}{0.286} \\
\hline
\end{tabular}

HpSA: Helicobacter pylori stool antigen, NS: Nephrotic syndrome.

Data are shown as numbers and percent and analyzed by chi-square test.

Table 3 Distribution of renal histopathology among nephrotic syndrome children with positive and negative helicobacter pylori stool antigen (HpSA) tests

\begin{tabular}{|c|l|l|l|}
\hline Renal histopathology & Positive HpSA test & Negative HpSA test & p value \\
\hline Biopsied NS cases (total number =38) & $20(52.63 \%)$ & $18(47.37 \%)$ & 0.648 \\
\hline -Proven MCD & $9(45 \%)$ & $1(5.55 \%)$ & 0.013 \\
\hline -Mesangioproliferative GN & $6(30 \%)$ & & 0.047 \\
\hline -FSGS & & $10(55.55 \%)$ & 0.363 \\
\hline -Membranoproliferative GN & $4(20 \%)$ & $1(5.55 \%)$ & 0.3 \\
\hline -IgA nephropathy & $1(5 \%)$ & $3(16.66 \%)$ & \\
\hline Presumed MCD (non-biopsied SSNS, n=59) & $21(35.59 \%)$ & $3(16.66 \%)$ & - \\
\hline Total MCD (proven plus presumed MCD) & $30(43.48 \%)$ & $38(64.41 \%)$ & 0.0018 \\
\hline
\end{tabular}

FSGS: Focal segmental glomerulosclerosis, GN: Glomerulonephritis, HpSA: Helicobacter pylori stool antigen, MCD: Minimal change disease, N: Number, SSNS: Steroid sensitive nephrotic syndrome. Data are shown as numbers and percent and analyzed by chi-square and fisher exact tests.

The high dose of steroid therapy was associated with group (Odds ratio $=3.8 ; 95 \%$ confidence interval $=$ a 3.8-fold higher risk of H.pylori infection among NS

1.3-11.3) (Table 4). 
Table 4 Logistic regression analysis of the risk factors associated with positive helicobacter

pylori stool antigen test in children with primary nephrotic syndrome

\begin{tabular}{|c|c|c|c|c|}
\hline Risk factors & Total & Positive HpSA test & $\mathrm{p}$ value & OR $(95 \% \mathrm{CI})$ \\
\hline Overall & 100 & $44(44 \%)$ & & \\
\hline \multicolumn{5}{|l|}{ Age (years) } \\
\hline$\leq 6$ & 31 & $15(48.4 \%)$ & 0.554 & $1.3(0.6-3)$ \\
\hline$>6$ & 69 & $29(42 \%)$ & & reference \\
\hline \multicolumn{5}{|l|}{ Sex } \\
\hline Male & 67 & $27(40.3 \%)$ & 0.288 & $0.63(0.27-1.5)$ \\
\hline Female & 33 & $17(51.5 \%)$ & & reference \\
\hline \multicolumn{5}{|l|}{ Total steroid duration (years) } \\
\hline$\leq 5$ & 78 & $31(39.7 \%)$ & 0.106 & $0.45(0.2-1.2)$ \\
\hline$>5$ & 22 & $13(59.1 \%)$ & & reference \\
\hline \multicolumn{5}{|l|}{ Steroid dose at time of study } \\
\hline -Low dose $(<1 \mathrm{mg} / \mathrm{kg} / \mathrm{d})$ & 50 & $24(48 \%)$ & 0.427 & $1.47(0.56-3.87)$ \\
\hline -High dose $(>1 \mathrm{mg} / \mathrm{kg} / \mathrm{d})$ & 24 & $10(41.7 \%)$ & 0.012 & $3.8(1.3-11.3)$ \\
\hline -Off steroids & 26 & $10(38.5 \%)$ & - & reference \\
\hline
\end{tabular}

CI: Confidence interval, FSGS: Focal segmental glomerulosclerosis, GN:Glomerulonephritis, HpSA: Helicobacter pylori stool antigen, OR: Odds ratio. Regression model included all significant variables in bivariate analysis (Constant $=-0.802$, Model $\chi^{2}=8.106 ; \mathrm{p}=0.044$, predicted percentage $=63 \%$ ).

\section{Discussion}

Several studies were conducted to assess the possible role of H.pyloi infection in NS pathogenesis ${ }^{16,19-21}$. The current study reported an insignificant difference between healthy controls and primary NS children with regard to HpSA test. This observation was in contrast to Zajaczkowska et al ${ }^{12}$, Moriyama et $\mathrm{al}^{16}$ and Nagashi- ma et $\mathrm{al}^{20}$ (Table 5). The only report that agrees with our results was that of Nutpho and Ukarapol ${ }^{13}$ (Table 5). This discrepancy could be explained by variability of the screening methods for H.pylori, different sample size and study design. This observation may negate the increased risk of H.pylori infection in children with primary NS. 
Table 5 Various studies about helicobacter pylori infection and nephrotic syndrome

\begin{tabular}{|c|c|c|c|}
\hline Study & Studied groups & Methods for $H$. pylori screening & Study outcome \\
\hline $\begin{array}{l}\text { Nagashima } \\
\text { et } \mathrm{al}^{20}\end{array}$ & 16 Adults with $\mathrm{MN}$ & $\begin{array}{l}\text { Serology and immuno-staining for } \\
\text { H.pylori in glomeruli }\end{array}$ & $\begin{array}{l}\text { They found specific antigens in glomeruli } \\
\text { and suggested H.pylori role in MN } \\
\text { pathogenesis. }\end{array}$ \\
\hline $\begin{array}{l}\text { Zajaczkowska et } \\
\mathrm{al}^{12}\end{array}$ & 20 children with NS & Urea breath test & $\begin{array}{l}\text { NS children were more prone to H.pylori } \\
\text { than controls. The longer steroid therapy } \\
\text { was associated with a higher H.pylori } \\
\text { risk. }\end{array}$ \\
\hline Moriyama et $\mathrm{al}^{16}$ & $\begin{array}{l}32 \text { Adults with primary MN \& } \\
243 \text { controls }\end{array}$ & Serology & $\begin{array}{l}\text { H.pylori was higher in } \mathrm{MN} \text { than } \\
\text { controls }(\mathrm{p}<0.05) \text {. Its eradication } \\
\text { reduced proteinuria in } 3 \text { of } 4 \\
\text { MN cases who received steroids. }\end{array}$ \\
\hline $\begin{array}{l}\text { Nutpho \& } \\
\text { Ukarapol }^{13}\end{array}$ & $\begin{array}{l}60 \text { immunocompromised } \\
\text { Thai children including } \\
9 \text { NS patients }\end{array}$ & Rapid HpSA test & $\begin{array}{l}\text { One out of } 9 \text { NS children was positive for } \\
\text { H.pylori antigens. }\end{array}$ \\
\hline Sugimoto et $\mathrm{al}^{21}$ & $\begin{array}{l}\text { A 34-years old Japanese } \\
\text { woman with stage I MN }\end{array}$ & $\begin{array}{l}\text { Histopathology and immuno- } \\
\text { staining for H.pylori antigens in } \\
\text { renal glomeruli }\end{array}$ & $\begin{array}{l}\text { No H.pylori antigens } \\
\text { deposited in the glomeruli. H.pylori } \\
\text { eradication reduced proteinuria. }\end{array}$ \\
\hline El-Latif et $\mathrm{al}^{9}$ & $\begin{array}{l}60 \text { immunocompromised } \\
\text { Egyptian children including } 15 \\
\text { NS patients \& } 30 \text { healthy } \\
\text { controls }\end{array}$ & Serology & $\begin{array}{l}\text { Seroprevalence of H.pylori was higher in } \\
\text { secondary immunodeficiency than } \\
\text { controls }(p=0.02) \text { and } \\
\text { insignificantly higher in malignancy than } \\
\text { NS }(p=0.51) .\end{array}$ \\
\hline Caliskan et $\mathrm{al}^{19}$ & $\begin{array}{l}59 \text { adults ( } 35 \mathrm{MN}, \\
12 \text { IgA nephropathy \& } \\
12 \text { FSGS) }\end{array}$ & $\begin{array}{l}\text { Rapid HpSA test \& immuno- } \\
\text { staining for H.pylori antigens in } \\
\text { renal glomeruli. }\end{array}$ & $\begin{array}{l}\text { Negative staining for H.pylori antigens in } \\
\text { renal glomeruli. H.pylori infection was } \\
\text { higher in IgA nephropathy }(83 \%) \text { than } \\
\text { MN }(54 \%)(\mathrm{p}=0.045) \text {. } \\
\text { H.pylori eradication decreased proteinuria } \\
\text { in MN patients; however spontaneous } \\
\text { remission could not be excluded. }\end{array}$ \\
\hline Dede et $\mathrm{al}^{24}$ & $\begin{array}{l}33 \text { adults (10 IgA nephropathy, } \\
7 \mathrm{MN} \text {, } \\
6 \text { mesangioproliferative GN, } 5 \\
\text { FSGS and } \\
5 \text { membranoproliferative GN) }\end{array}$ & Urea breath test \& histopathology & $\begin{array}{l}\text { H.pylori eradication failed to improve } \\
\text { proteinuria }(\mathrm{p}=0.99) \text {. }\end{array}$ \\
\hline
\end{tabular}

FSGS: Focal segmental glomerulosclerosis, GN: Glomerulonephritis, HpSA: Helicobacter pylori stool antigen, MN: Membranous nephropathy, NS: Nephrotic syndrome

On reviewing the literature, some authors reported presence of H.pylori antigens in glomeruli of renal biopsy specimens, but failed to confirm the link between the organism and NS pathogenesis ${ }^{20}$. They depended upon the presumed hypothesis that H.pylori could increase the risk of NS through immune-mediated reactions induced by direct antigenic effects ${ }^{20}$ or auto-antibodies formation ${ }^{22,23}$. The effects of H.pylori eradication on the treatment response was also tested in few cohort studies. Some authors found insignificant improvement in proteinuria after H.pylori eradication ${ }^{24}$, while others failed to prove that the improvement in proteinuria was due to H.pylori treatment only and not due to spontaneous remission ${ }^{19}$. Even for studies that proved improvement in proteinuria due to eradication of H.pylori, the small sample size limits generalization of their results \{three out of studied 32 cases in Moriyama et $\mathrm{al}^{16}$ and a case report by Sugimoto et $\left.\mathrm{al}^{21}\right\}$. Thus further randomized controlled trials (RCTs) with larger sample sizes are needed to provide more details about the exact pathogenic role of H.pylori in NS.

Moreover, the current study was the first to describe an insignificant difference between SSNS and SRNS chil- 
dren with regard to H.pylori infection. However, the high dose of steroid therapy was associated with a higher H.pylori risk among NS group, possibly due to the immuno-suppressant effect of the high-dose steroid ${ }^{9}$.

In the current study, the age of patients was not considered a risk factor for H.pylori among NS group. This observation copes with a previous national report ${ }^{9}$. Other international studies with larger sample sizes proved that H.pylori infection rates increase with advancing age, mostly due to cumulative frequencies ${ }^{25-27}$. Also, the gender of patients was not a risk factor for H.pylori infection that agrees with many international reports ${ }^{25,26,28,29}$. However, other studies reported male predominance ${ }^{27,30}$. This discrepancy could be explained by differences in study design and sample size.

Unexpectedly, the total duration of steroids therapy did not increase the risk for H.pylori, possibly due to interrupted courses of therapy with variable intervals that increased the therapy duration among patients. This finding was in contrast to Zajaczkowska et $\mathrm{al}^{12}$.

Concerning total biopsied NS cases and MCD (proven plus presumed cases), the insignificant differences found between those with positive and negative HpSA tests suggest lack of association between H.pylori infection and renal histopathology in NS group. Our findings were in variance with Nagashima et $\mathrm{al}^{20}$

\section{Conclusion}

The current study provides useful information about H.pylori prevalence among primary NS children in Egypt. Our study negates the increased risk of H.pylori infection in children with primary NS. The high dose of steroid therapy was associated with a higher H.pylori risk among those patients. Large scale RCTs multicenter studies are still needed.

\section{Limitations of the study}

A single center association study with limited studied H.pylori risk factors, lack of long term follow-up and a potential selection bias of patients.

\section{Funding section}

This research received no grant from any funding agency in the public, commercial or not-for-profit sectors.

\section{Declaration of interest}

The authors declare no conflicts of interest.

\section{List of abbreviations}

CI: Confidence interval

FSGS: Focal segmental glomerulosclerosis

GN: Glomerulonephritis

H.pylori: Helicobacter pylori

HpSA: Helicobacter pylori stool antigen

MCD: Minimal change disease

$\mathrm{MN}$ : Membranous nephropathy

NS: Nephrotic syndrome

OR: Odds ratio

RCTs: Randomized controlled trials

SPSS: Statistical Package For The Social Sciences

SRNS: Steroid resistant nephrotic syndrome

SSNS: Steroid sensitive nephrotic syndrome

\section{References}

1. Chanchlani R, Parekh RS. Ethnic differences in childhood nephrotic syndrome. Front Pediatr 2016;4:39

2. El-Hakim IZ, Mohammed AA, Afifi HM, El-Sayed SA. Circulating dendritic cells in pediatric patients with nephrotic syndrome. Egypt J Pediatr Allergy Immunol 2011;9(1):41-47

3. Segarra-Medrano A, Carnicer-Cáceres C, Arbós-Via MA, Quiles-Pérez MT, Agraz-Pamplona I, Ostos-Roldán E. Biological markers of nephrotic syndrome: a few steps forward in the long way. Nefrologia 2012;32(5):558-572

4. Wroblewski LE, Peek RM, Wilson KT. Helicobacter pylori and gastric cancer: factors that modulate disease risk. Clin Microbiol Rev 2010; 23(4):713-739

5. Hooi JKY, Lai WY, Ng WK, Suen MMY, Underwood FE, Tanyingoh D, et al. Global prevalence of Helicobacter pylori infection: systematic review and meta-analysis. Gastroenterology 2017;153(2):420-429

6. Muhsen K, Ornoy A, Akawi A, Alpert G, Cohen D. An association between Helicobacter pylori infection and cognitive function in children at early school age: a community-based study. BMC Pediatr 2011;11:43

7. Zamani M, Ebrahimtabar F, Zamani V, Miller WH, Alizadeh-Navaei R, Shokri-Shirvani J, et al. Systematic review with meta-analysis: the worldwide prevalence of Helicobacter pylori infection. Aliment Pharmacol Ther 2018; 47(7):868-876

8. Mohammad MA, Hussein L, Coward A, Jackson SJ. Prevalence of Helicobacter pylori infection among Egyptian children: impact of social background and effect on growth. Public Health Nutr 2008;11(3):230-236

9. El-Latif AMA, Ali ASA, Abdel-Hady M, Borai MBM. Seroprevalence of Helicobacter pylori in secondary immunocompromised children. J Am Sci 2011;7(9):592-595 
10. Tan HJ, Goh KL. Extragastrointestinal manifestations of Helicobacter pylori infection: facts or myth? A critical review. J Dig Dis 2012;13(7):342-349

11. Fathy G, Said M, Abdel-Raheem SM, Sanad H. Helicobacter Pylori Infection: A possible predisposing factor in chronic plaque-type psoriasis. J Egypt Women Dermatol Soc 2010;7(1):39-43

12. Zajaczkowska M, Durakiewicz T, Papierkowski A. The assessment of Helicobacterpylori eradication with the urea breathing test (13C UBT). Pol Merkur Lek organ Pol Tow Lek 2000;8(46):230-232

13. Nutpho P, Ukarapol N. Helicobacter pylori and immunocompromised children. Emerg Infect Dis 2006;12(1):171-172

14. Gipson DS, Massengill SF, Yao L, Nagaraj S, Smoyer WE, Mahan JD, et al. Management of childhood onset nephrotic syndrome. Pediatrics 2009;124(2):747-757 15. Bagga A. Revised guidelines for management of steroid-sensitive nephrotic syndrome. Indian J Nephrol 2008;18(1):31-39

16. Moriyama T, Kaneko T, Fujii M, Tsubakihara Y, Kawano S, Imai E. High prevalence of Helicobacter pylori infection in Japanese patients with membranous nephropathy. Aliment Pharmacol Ther 2006;24:189-193

17. Lombel RM, Gipson DS, Hodson EM. Treatment of steroid-sensitive nephrotic syndrome: new guidelines from KDIGO. Pediatr Nephrol 2013;28:415-426

18. Raja K, Parikh A, Webb H, Hothi D. Use of a lowdose prednisolone regimen to treat a relapse of steroid-sensitive nephrotic syndrome in children. Pediatr Nephrol 2017;32(1):99-105

19. Caliskan B, Yazici H, Caliskan Y, Ozluk Y, Gulluoglu M, Kilicaslan I, et al. The effects of Helicobacterpylori eradication on proteinuria in patients with primary glomerulonephritis. Int J Nephrol 2014:180690

20. Nagashima R, Maeda K, Yuda F, Kudo K, Saitoh $\mathrm{M}$, Takahashi T. Helicobacter pylori antigen in the glomeruli of patients with membranous nephropathy. Virchows Arch 1997;431(4):235-239

21. Sugimoto T, Furukawa T, Maeda T, Somura M, Uzu T, Kashiwagi A. Marked reduction of proteinuria after eradication of gastric Helicobacter pylori infection in a patient with membranous nephropathy: coincidental or associated? Intern Med 2007;46(17):1483-1484

22. Ma JY, Borch K, Sjöstrand SE, Janzon L, Mårdh S. Positive correlation between $\mathrm{H}, \mathrm{K}$-adenosine triphosphatase autoantibodies and Helicobacter pylori antibodies in patients with pernicious anemia. Scand J Gastroenterol 1994;29(11):961-965

23. Negrini R, Lisato L, Zanella I, Cavazzini L, Gullini S, Villanacci V, et al. Helicobacter pylori infection induces antibodies cross-reacting with human gastric mucosa. Gastroenterology 1991;101(2):437-445

24. Dede F, Ayli D, Gonul I, Yuksel O, Ozturk R, Yildiz A, et al. The effect of Helicobacter pylori eradication on proteinuria in patients with primary glomerulonephritis. Arch Med Sci 2015;11(4):764-769

25. Soltani J, Amirzadeh J, Nahedi S, Shahsavari S. Prevalence of helicobacter pylori infection in children, a population-based cross-sectional study in west iran. Iran J Pediatr 2013;23(1):13-18

26. Oleastro M, Pelerito A, Nogueira P, Benoliel J, Santos A, Cabral J, et al. Prevalence and incidence of Helicobacter pylori Infection in a healthy pediatric population in the Lisbon area. Helicobacter 2011;16(5):363372

27. Hestvik E, Tylleskar T, Kaddu-Mulindwa DH, Ndeezi G, Grahnquist L, Olafsdottir E, et al. Helicobacter pylori in apparently healthy children aged 0-12 years in urban Kampala, Uganda: a community-based cross sectional survey. BMC Gastroenterol 2010;10:62

28. Talaiezadeh A, Borhani M, Moosavian M, Rafiei A, Kazem Neisi A, Hajiani E, et al. Prevalence of Helicobacter pylori Infection evaluated by Stool antigen test in Khuzestan Province since September to October 2009, south-west of Iran: a population based study. Jundishapur J Microbiol 2013; 6(2):100-104

29. Nguyen BV, Nguyen KG, Phung CD, Kremp O, Kalach N, Dupont C, et al. Prevalence of and factors associated with Helicobacter pylori infection in children in the north of Vietnam. Am J Trop Med Hyg 2006;74(4):536-539

30. de Martel C, Parsonnet J. Helicobacter pylori infection and gender: a meta-analysis of population-based prevalence surveys. Dig Dis Sci 2006;51(12):2292-2301 